\title{
Fused Thiophene-Split Oligothiophenes with High Ionization Potentials for OTFTs
}

\author{
Yanying Zhang,b, Musubu Ichikawa**, Jinya Hattori, Tatsuya Kato, Ayumi Sazaki, \\ Shusuke Kanazawa, Shimpei Kato, ChunHan Zhang, Yoshio Taniguchi ${ }^{\mathrm{b}}$ \\ a State Key Laboratory for Corrosion and Protection, \\ Institute of Metal Research, Chinese Academy of Sciences, \\ 72 Wenhua Road, Shenyang 110016, P.R. China \\ ${ }^{\mathrm{b}}$ Functional Polymer Science Course, Faculty of Textile Science and \\ Technology, Shinshu University \\ 3-15-1 Tokita, Ueda City, Nagano 386-8567, JAPAN \\ * Corresponding author. Tel.: +81-268-21-5498; fax: +81-268-21-5413 \\ E-mail address: musubu@shinshu-u.ac.jp (M. Ichikawa)

\section{zhangyy@imr.ac.cn (Y. Y. Zhang)}

\begin{abstract}
Fused thiophene-split oligothiophenes were synthesized by Suzuki coupling. The relationship between the structure of these fused thiophene-split oligothiophenes and DH-6T $(\alpha, \omega$ dihexylsexithiophene) and their performance in OTFTs was discussed. The realignment of HTTfTTTH (2,5-Bis-(5'-hexyl-[2,2']bithiophenyl-5-yl)-thieno[3,2-b] thiophene) molecule on the substrate after annealing was revealed by X-ray diffraction and atomic force microscopy. A similar but novel compound, TTfTTT (2,5-Bis-[2,2']bithiophenyl-5-yl-thieno[3,2-b]thiophene), was also prepared and evaluated as an organic transistor material. Air stabilities of these three compounds in OTFT devices were affected mainly by chemical properties, but also by the ionization potentials $\left(I_{p}\right)$ of these materials. Among the three compounds, HTTfTTTH had a higher $I_{p}$ because the thiophene sequence was split by fused thiophene and the best air stability, due to the end-capping of its active $\alpha$-positions by hexyl substitution.
\end{abstract}




\section{Introduction}

Organic thin film transistors (OTFTs) are of interest for low-cost, large-area electronic applications, such as active-matrix displays, flexible microelectronics and electronic paper [1].Various organic semiconducting materials have been used in the active layers of these OTFTs. In this context, thiophene oligomers and polymers have been reported as potential candidates for OTFT materials because of their ease of chemical modification and rather good charge carrier mobility, but their instability in the atmosphere is still a problem. Due to low ionization potential $\left(I_{p}\right)$, which thermodynamically increases probability for electron donation, oxidation in the atmosphere tends to degrade the performance of these materials. However, where different $\pi$-conjugated central units are introduced and the thiophene sequence is divided into more than two parts to inhibit delocalization or shorten $\pi$-conjugation length, resulting in higher ionization potential $\left(I_{p}\right)$, which increased air stability [2]. Recently, the combination of fused thiophenes in the backbones of the thiophene oligomers and polymers has emerged [3], especially in I. Mcculloch et al's work with a series of excellent field-effect materials, such as PBTTT based on a combination of thiophene sequences and fused thiophene [4]. These results indicate that introducing fused thiophene into oligothiophenes as a central unit will result in good OTFT materials. To the best of our knowledge, there has been only one report, by Lim et al, of fused thiophene-split oligothiophene, 2,5-Bis-(5'-hexyl-[2,2']bithiophenyl-5-yl)-thieno[3,2-b] thiophene (HTTfTTTH), as an OTFT material [3]. However, this compound showed poor carrier mobility and its air stability had not been described. Our work suggests that fused thiophene-split oligothiophenes are good candidate materials for air-stable OTFTs. Here we report on (1) synthesis of novel fused thiophene-split oligothiophene TTfTTT and hexyl-end-capped analogue HTTfTTTH and (2) the performance of fused thiophene-split oligothiophenes in OTFT devices.

\section{Experimental}

\section{Synthesis}

All reactions were carried out under a nitrogen environment. Solvents were purified by standard methods before use. Elemental analyses were determinated by PERKIN ELMER Series II CHNS/O Analyzer 2400. Melting behavior was determined with a differential scanning calorimeter (DSC, Seiko Instrument DSC6200 Thermosystem) at a scanning rate of $10 \mathrm{~K} / \mathrm{min}$. DH-6T was purchased from Sigma-Aldrich and purified by sublimation before use. 


\section{Preparation of TTfTTT}

Tetrakis(triphenylphosphine)palladium $\left(\mathrm{Pd}\left(\mathrm{PPh}_{3}\right)_{4}\right)$ (87 mg, $\left.0.075 \mathrm{mmol}\right)$, 2,5- Dibromothieno[3,2b]thiophene (447 mg, $1.5 \mathrm{mmol}$ ) and 5-(4,4,5,5-tetramethyl-1,3,2 -dioxaborolan-2-yl)-2,2'bithiophene (0.96 g, $3.4 \mathrm{mmol})$ were added into a two-neck Schlenk flask. The flask was deoxygenated by vacuum and protected with nitrogen. Deoxygenated toluene (30mL) and $2 \mathrm{M}$ aqueous $\mathrm{K}_{2} \mathrm{CO}_{3}$ solution $(10 \mathrm{~mL})$ bubbled with nitrogen were injected using syringes. The reaction mixture was heated for 24 hours under reflux, then cooled, filtered, and washed with $100 \mathrm{ml}$ of hot water three times, and with $100 \mathrm{~mL}$ of toluene two times. Crude TTfTTT was obtained after vacuum drying at $60^{\circ} \mathrm{C}$. Yield: $0.50 \mathrm{~g}(71.4 \%$ of theoretical value) brown crystals. Purification by sublimation gave bright orange crystals. Analytical Data: mass spectroscopy (MALDI-TOF), $\mathrm{m} / \mathrm{e}=469.30$; melting point, $308.2^{\circ} \mathrm{C}$; decomposition occurs from $369^{\circ} \mathrm{C}$; elemental analysis, calcd for $\mathrm{C}_{22} \mathrm{H}_{12} \mathrm{~S}_{6}$ : C, 56.37, H, 2.58, S, 41.05\%. Found: C, 56.27; H, 2.66, S, 41.02\%.

\section{Preparation of HTTfTTTH}

HTTfTTT was prepared from 5-(4,4,5,5-tetramethyl-1,3,2-dioxaborolan-2-yl)-5'-hexyl -l-2,2'bithiophene $(1.28 \mathrm{~g}, 3.4 \mathrm{mmol})$ as described in the above procedure. Yield: $0.82 \mathrm{~g}$ (86.0\% of theoretical value) bright orange crystal. The crude material was purified by sublimation. Analytical Data: mass spectroscopy (MALDI-TOF), $\mathrm{m} / \mathrm{e}=637.83$; melting point, $254.6^{\circ} \mathrm{C}$. There was a weak endothermic peak at $128^{\circ} \mathrm{C}$ and decomposition started at $343^{\circ} \mathrm{C}$ occurred. Elemental analysis, calcd for $\mathrm{C}_{34} \mathrm{H}_{36} \mathrm{~S}_{6}$ : C, 64.10, H, 5.70, S, 30.20\%. Found: C, 63.96; H, 5.71, S, 30.40\%.

\section{Fabrication and measurement}

Top-contact OTFTs devices were fabricated using TTfTTT, HTTfTTTH or DH-6T (Fig.1) on silicon wafers as follows: The wafers were treated with oxygen plasma for $40 \mathrm{~min}$, then immediately immersed into a $0.1 \mathrm{M}$ anhydrous toluene solution of octyltrichlorosilane (OTS-8) at $70^{\circ} \mathrm{C}$ for 30 min, rinsed with pure toluene and isopropanol, and then dried by air gun. The dielectric surface was characterized before and after OTS treatment using water contact angle measurements, which were $47^{\circ}$ after cleaning and $>97^{\circ}$ after OTS monolayer formation.

Then organic materials were thermally evaporated $\left(\sim 230^{\circ} \mathrm{C}\right)$ onto the substrates at the rate of $0.3 \AA / s$ to form a $60 \mathrm{~nm}$ film. The base pressure for the deposition was $4.0 \times 10^{-6}$ Torr. Finally, Au was thermally evaporated onto the organic layers through a shadow mask to form source and drain electrodes. Channel length and width were $2 \mathrm{~mm}$ and $30 \mu \mathrm{m}$, respectively. OTFT performance was 
measured under atmospheric conditions using an Agilent semiconductor parameter analyzer (B1500A).

Using powder samples, the photoelectron emission yield spectra were measured with a Riken-Keiki AC2 at an irradiation light power of $10 \mathrm{nW} / \mathrm{cm}^{2}$. The X-ray diffraction (XRD) patterns were measured with a Rigaku Rotaflex using $\mathrm{Cu} K \alpha$ radiation (wavelength $=1.5406 \AA$ ) at $\theta / 2 \theta$ geometry. The sample films, which all had thicknesses of $60 \mathrm{~nm}$, were deposited onto $\mathrm{SiO}_{2} / \mathrm{Si}$ substrates that had been prepared with the same procedure as the OTFTs. Tapping-mode atomic force microscope (AFM) images were recorded using a Seiko Instruments SPA-300/SPI3800 probe system. The single crystal structure was analyzed with a Bruker AXS APEX II.

\section{Results and Discussion}

\section{Ionization Potentials}

Figure 2 shows the photoelectron emission yield spectra for DH-6T, HTTfTTTH and TTfTTT. The $I_{p}$ values for these compounds were estimated based on these spectra. DH-6T, a commonly used continuous sequence oligothiophene [5], had the lowest $I_{p}$ of about $4.8 \mathrm{eV}$. When a fused thiophenesplit sequence was introduced, $I_{p}$ 's for HTTfTTTH and TTfTTT were higher, $5.0 \mathrm{eV}$ and $5.2 \mathrm{eV}$ respectively. This indicates that these fused thiophene-split oligothiophenes are good candidates for further research on air-stable OTFT devices [6].

\section{Molecular Orientation in Thin-film State}

Figures 3 and 4 show the XRD measurements of the oligothiophenes. As shown in Fig. 3a-d, the patterns for TTfTTT prepared at different substrate temperatures (room temperature, 80, 100 and $\left.120^{\circ} \mathrm{C}\right)$, were almost the same. A peak appeared at $2 \theta=3.94^{\circ}(d=22.4 \AA)$, and two other peaks appeared at $2 \theta=7.81^{\circ}$ and $2 \theta=11.7^{\circ}$, which corresponded to a higher order diffraction of $d=22.4$ $\AA$. The derived $d$ spacing of $22.4 \AA$ was practically identical to the $c$-axis length observed in the crystal structure (Fig. 5, c $=22.7 \AA)$. Other peaks at $2 \theta=15.7^{\circ}(d=5.63 \AA), 19.6^{\circ}(d=4.52 \AA)$, and $23.6^{\circ}(d=3.76 \AA$ ) were also assigned to higher order reflection of the $c$-axis. These progressive peaks indicated that TTfTTT molecules aligned perpendicularly in the film. The AFM in Fig. 7 also showed that grains had so called step-terrace structures in which the step height of about $2.5 \mathrm{~nm}$ (Fig. 7a) was almost the same as the length of the $c$-axis, also suggesting perpendicular alignment of the TTfTTT molecules. 
Figure 4. shows the different XRD patterns of HTTfTTTH thin films with no annealing and after annealing at 80,100 and $110^{\circ} \mathrm{C}$. With no annealing (Fig. 4a), the main peak at $2 \theta=2.70^{\circ}$ gave the largest d-space of $32.7 \AA$, which probably corresponded to an upright orientation. The molecular length of $36.3 \AA$ calculated by MM2 potential on Chem3D indicated that HTTfTTTH molecules had a tilt angle of about $25^{\circ}$. Another small peak was located to the right of the main peak at about $2 \theta=$ 3.16 ( $d=27.9 \AA)$, which indicated that some molecules aligned on the substrate with larger tilt angles. With annealing at $80^{\circ} \mathrm{C}$ for $1 \mathrm{hr}$, the right peak was higher than with no annealing, as shown in Fig. 4b. As can be seen in the AFM images of thin films shown in Fig. 8, two different types of grains can be distinguished. The morphology of the two crystallographic phases [7], mainly long and narrow grains phase appearing at lower temperatures, and only the plate-like grains phase were observed at annealing temperatures of 100 and $110^{\circ} \mathrm{C}$. These XRD and AFM results showed that the molecules realigned in the thin film during annealing. This realignment of HTTfTTTH molecules that occured even at such a low annealing temperature may be caused by flexibility in the long hexyl chain end-cap.

\section{OTFT characteristics}

In Figure 6 can be seen $I_{D}-V_{D}$ and $I_{D}-V_{G}$ characteristics of TTfTTT and HTTfTTTH OTFTs. Both devices exhibited p-type behavior. Table 1 shows the field effect mobilities $\left(\mu_{F E T}\right)$, threshold voltages $\left(V_{t h}\right)$, ON/OFF ratios, and subthreshold slopes of all the devices, where the $\mu_{F E T}$ and some other parameters were calculated from the saturated drain current $\left(I_{D}\right)$ using Equation (1).

$I_{D}=\mu_{F E T} \frac{W C_{i}}{2 L}\left(V_{G}-V_{t h}\right)^{2}$

where $C_{i}$ is the specific capacitance of the insulator, $L$ is channel length, $V_{G}$ is gate voltage, and $W$ is channel width. The hole mobilities of TTfTTT and HTTfTTTH were up to $0.12 \mathrm{~cm}^{2} / \mathrm{Vs}$ at room temperature and even with heat treatment there was no great change, which were from $0.08-0.12$ $\mathrm{cm}^{2} /$ Vs. Their mobilities were almost in the same order as DH-6T at room temperature, which was $0.09 \mathrm{~cm}^{2} /$ Vs. As shown in Table 1, there was no major difference in the $V_{t h}$ between TTfTTT and HTTfTTTH. While the OTFT made from TTfTTT had much better subthreshold slopes and ON/OFF ratio than HTTfTTTH and DH-6T, which both had hexyl end-caps. Comparing Fig. 6b and 6d, the on current of the two compounds was almost the same value, but the off current for HTTfTTTH was about 100 times that of TTfTTT. We are not yet sure of the reason for the higher off current at present, but it may have been affected by purity of the materials.

To test device stability, OTFT devices were stored unencapsulated and exposed to ambient light and 
moisture. The results show that HTTfTTTH with an $I_{p}$ of about $5.0 \mathrm{eV}$ maintained its characteristics better under atmospheric conditions than DH-6T with $4.8 \mathrm{eV}$ (Fig. 9). This suggests that the higher $I_{p}$ gave HTTfTTTH good air stability. As shown in Fig. 9, the mobility of TTfTTT decreased very quickly within only 5 days despite its higher $I_{p}(5.2 \mathrm{eV})$. TTfTTT was easily oxidized because its end-caps at $\alpha$-positions had no protection, which is the only difference between it and HTTfTTTH [2].The mobility of DH-6T tended to decrease, but more slowly than that of TTfTTT. These results suggest that the most important factor in obtaining good air stability is the chemical stability of the organic materials. The second factor is a large $I_{p}$ such as that of HTTfTTTH protected by hexyl endcaps at $\alpha$-positions.

\section{Conclusion}

Fused thiophene-split oligothiophenes were designed and synthesized with the aim of developing airstable OTFT materials with good $I_{p}$ values. Photoelectron emission yield spectra showed that this split-sequence oligomer has an $I_{p}$ value of $5.0 \mathrm{eV}$, higher than the $4.8 \mathrm{eV}$ of the corresponding continuous sequence oligothiophene. Evaluation of oligomers purified by sublimation in OTFTs showed that they are $p$-type organic semiconductors with carrier mobilities of up to $0.12 \mathrm{~cm}^{2} / \mathrm{Vs}$. XRD and AFM measurements indicated perpendicular alignment of the TTfTTT molecules on the film. This was reinforced by identification of the unit cell structure of a single TTfTTT crystal. The introduction of hexyl end-caps onto TTfTTT formed HTTfTTTH, which had improved air stability. It was possible to reveal the realignment of HTTfTTTH molecules in the film at higher annealing temperatures through XRD and AFM determination. Our current study indicates it is a promising approach for the creation of new stable semiconducting materials with high charge-transport mobility and good device performance by introducing fused thiophene unit to split oligothiophenes of continuous sequence with $\alpha$-position protection against chemical degradation.

\section{Acknowledgements}

This work was supported by the Japanese Ministry of Education, Culture, Sports, Science and Technology through CLUSTER. The authors thanked Bruker AXS Japan Co. Ltd. for analyzing the crystal structure of TTfTTT and also thanked Ms. Peggy Ahrens for valuable suggestion.

\section{References}

[1] M. Halik, H. Klauk. Adv. Mater. 2003, 15(11), 917-922. 
[2] a. S. Kanazawa, M. Ichikawa, Y. Fujita, R. Koike, T. Koyama and Y. Taniguchi. Org. Electron. 2008, 9, 425-431. b. N. S. Cho, S. Cho, M. Elbing, J. K. Lee, R. Yang, J. H. Seo, K. Lee, G. C. Bazan and A. J. Heeger. Chem. Mater., 2008, 20 (20), 6289-6291. c. W. Porzio, S. Destri, U. Giovanella, M. Pasini, L. Marin, M. D. Iosip, M. Campione. Thin Solid Films 2007, 515, 7318-7323. d. H. Tian, J. Wang, J. Shi, D. Yan, L. Wang, Y. Geng and F. Wang. J. Mater. Chem., 2005, 15, 3026-3033.

[3] a. E. Lim, B.-J. Jung, H.-K. Shim, T. Taguchi, B. Noda, T. Kambayashi, T. Mori, K. Ishikawa, H. Takezoe and L.-M. Do. Org. Electron.. 2006, 7, 121-131. b. H. Pan, Y. Li, Y. Wu, P. Liu, B. S. Ong, S. Zhu and G. Xu. J. Am Chem. Soc. 2007, 129, 4112-4113.c. L. San Miguel, W. W. III Porter, A. J. Matzger, Org. Lett. 2007, 9(6), 1005-1008. d. H. Pan, P. Liu, Y. Li, Y. Wu, B. S. Ong, S. Zhu and G. Xu. Adv. Mater. 2007, 19, 3240-3243. e. R. J. Kline, D.M. DeLongchamp, D. A. Fischer, E. K. Lin, M. Heeney, I. McCulloch, M. F. Toney. Appl. Phys. Lett. 2007, 90(6), 062117/1062117/3. f. M. L. Chabinyc, M. F. Toney, R. J. Kline, I. McCulloch. J. Am. Chem. Soc. 2007, 129, 3226-3237. g. M. Heeney, C. Bailey, K. Genevicius, M. Shkunov, D. Sparrowe, S. Tiemey and I. McCulloch. J. Am. Chem. Soc. 2005, 127, 1078-1079. h. K. Takimiya, H. Ebata, K. Sakamoto, T. Izawa, T. Otsubo and Y. Kunugi. J. Am. Chem. Soc. 2006, 128, 12604-12605. i. Y. Li, Y. Wu, P. Liu, M. Birau, H. Pan, and B. S. Ong. Adv. Mater. 2006, 18, 3029-3032. j. C. Yang, S. Cho, R. C. Chiechi, W. Walker, N. E. Coates, D. Moses, A. J. Heeger, and F. Wudl. J. Am. Chem. Soc., 2008, 130 (49), 16524-16526.

k. H. H. Fong, V. A. Pozdin, A. Amassian, G. G. Malliaras, D.-M. Smilgies, M. He, S. Gasper, F. Zhang, and M. Sorensen. J. Am. Chem. Soc., 2008, 130 (40), 13202-13203.

l. L. S. Miguel and A. J. Matzger. Macromolecules, 2007, 40 (26), 9233-9237.

m. J. Liu, R. Zhang, G. Sauve, T. Kowalewski and R. D. McCullough. J. Am. Chem. Soc., 2008, 130 (39), 13167-13176.

[4] a.M. Heeney, W. Zhang, I. Mcculloch, EP1753768(WO2005/121150). b. M. Heeney, I. Mcculloch. US2007246704. c. I. Cabrera, U. Falk, W. Hickel, D. Lupo, U. Scheunemann, P. Boldt, M. Blenkle. US5684165. d. B. H. Hamadani, and D. J. Gundlach, I. McCulloch and M. Heeney. Appl. Phys. Lett. 2007, 91, 243512. e. D. M. DeLongchamp, R. J. Kline, E. K. Lin, D. A. Fischer, L. J. Richter, L. A. Lucas, M. Heeney, I. McCulloch and J. E. Northrup. Adv. Mater. 2007, 19, 833-837. f. B. H. Hamadani, and D. J. Gundlach, I. McCulloch and M. Heeney. Appl. Phys. Lett. 2007, 91, 243512. g. D. M. DeLongchamp, R. J. Kline, E. K. Lin, D. A. Fischer, L. J. Richter, L. A. Lucas, M. Heeney, I. McCulloch and J. E. Northrup. Adv. Mater. 2007, 19, 833-837. h. I. Mcculloch, M. Heeney, C. Bailey, K. Genevicius, I. Macdonald, M. Shkunov, D. Sparrowe, S. Tierney, R. Wagner, 
W. Zhang, M. L. Chabinyc, R. J. Kline, M. D. Mcgehee and M. F. Toney. Nat. Mater, 2006, 5, 328333.

[5] a. M. Halik, H. Klauk, U. Zschieschang, G. Schmid, S. Ponomarenko, S. Kirchmeyer, W. Weber. Adv. Mater. 2003, 15, 917. b. A. B. Chwang, E. L. Granstrom and C. D. Frisbie. Adv. Mater. 2000, 12 (4), 285-288. с. C. D. Dimitrakopoulos, B. K. Furman, T. Graham, S. Hegde, S. Purushothaman. Synth. Met. 1998, 92, 47-52. d. S. Blumstengel, N. Koch, S. Sadofev, P. Schäfer, H. Glowatzki, R. L. Johnson, J. P. Rabe and F. Henneberger. Appl. Phys. Lett. 2008, 92, 193303. e. M. Campione, A. Sassella, M. Moret, A. Thierry, B. Lotz. Thin Solid Films. 2006, 500, 169-173.

[6] a. X. Zhang and A. J. Matzger. J. Org. Chem, 2003, 68(25), 9813-9815. b. J. Locklin, M. M. Ling, A. Sung, M. E. Roberts and Z. Bao. Adv. Mater. 2006, 18, 2989-2992. c. H. K. Tian, J. W. Shi, D. H. Yan, L. X. Wang, Y. H. Geng and F. S. Wang. Adv. Mater. 2006, 18, 2149-2152.

[7] I. P. M. Bouchoms, W. A. Schoonveld, J. Vrijmoeth, T. M. Klapwijk. Synth.Met. 1999, 104, 175-178.

\section{Figure Captions}

Table 1. Electrical characteristics of oligothiophenes OTFTs in atmosphere.

Figure 1. Chemical structures of fused thiophene-split or continuous sequence oligothiophenes

Figure 2. Photoelectron emission yield spectra of oligothiophenes.

Figure 3. XRD patterns of TTfTTT thin films deposited on $\mathrm{Si} / \mathrm{SiO}_{2}$ with substrate control at (a) room temperature, (b) $80^{\circ} \mathrm{C}$, (c) $100^{\circ} \mathrm{C}$, and (d) $120^{\circ} \mathrm{C}$.

Figure 4. XRD patterns of HTTfTTTH thin films deposited on $\mathrm{Si} / \mathrm{SiO}_{2}$ without substrate control (a) no annealing and after annealing at (b) $80^{\circ} \mathrm{C}$, (c) $100^{\circ} \mathrm{C}$, and (d) $120^{\circ} \mathrm{C}$.

Figure 5. TTfTTT unit cell. (Crystal class: monoclinic, Space group: P21, Cell Constants: $a=5.8293 \AA ; b=7.2580 \AA ; c=22.700 \AA ; \beta=94.966^{\circ}$ ). The crystal structure has been deposited at the Cambridge Crystallographic Data Centre and allocated the deposition number Summary of Data CCDC 697364 
Figure 6. $\mathrm{I}_{\mathrm{D}}-\mathrm{V}_{\mathrm{D}}$ and $\mathrm{I}_{\mathrm{D}}-\mathrm{V}_{\mathrm{G}}$ characteristics of $(\mathrm{a}, \mathrm{b})$ TTfTTT and (c, d) HTTfTTTH.

Figure 7. AFM of TTfTTT thin films deposited on $\mathrm{Si} / \mathrm{SiO}_{2}$ with substrate control at (a) room temperature and the step height of grains, (b) $80^{\circ} \mathrm{C}$, (c) $100^{\circ} \mathrm{C}$, (d) $120^{\circ} \mathrm{C}$.

Figure 8. AFM of HTTfTTTH thin films deposited on $\mathrm{Si} / \mathrm{SiO}_{2}$ without substrate control (a) no annealing and after annealing at (b) $80^{\circ} \mathrm{C}$, (c) $100^{\circ} \mathrm{C}$, and (d) $120^{\circ} \mathrm{C}$.

Figure 9. The mobility stabilities of TTfTTT, HTTfTTTH and DH-6T in atmosphere 
Table 1. Electrical characteristics of oligothiophenes OTFTs in atmosphere.

\begin{tabular}{c||cccc}
\hline & $\mu_{\mathrm{FET}}\left(\mathrm{cm}^{2} / \mathrm{Vs}\right)$ & $\mathrm{V}_{\text {th }}(\mathrm{V})$ & ON/OFF ratio & $\begin{array}{c}\text { subthreshold slope } \\
\text { (V/decade) }\end{array}$ \\
\hline TTfTTT & 0.120 & -0.46 & $10^{5}$ & 2.83 \\
HTTfTTTH & 0.126 & -2.90 & $10^{3}$ & 12.0 \\
DH-6T & 0.092 & -12.8 & $10^{3}$ & 8.8 \\
\hline
\end{tabular}




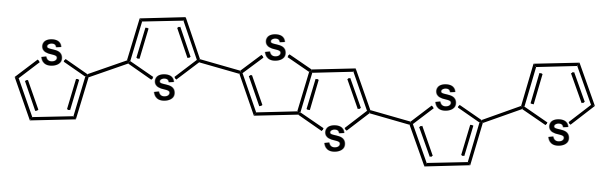

TTfTTT

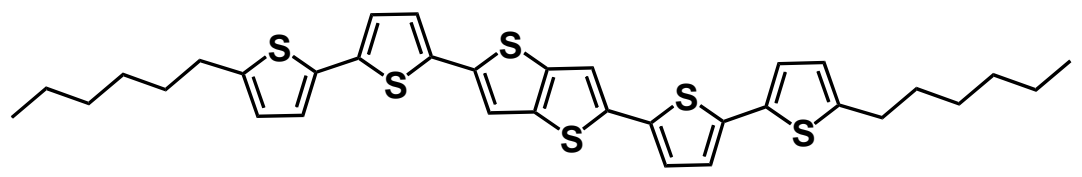

HTTfTTTH

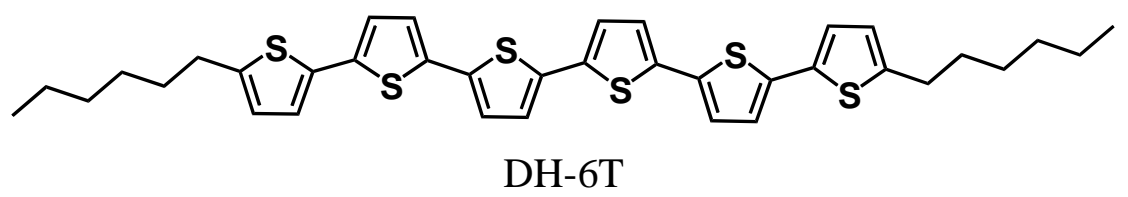

Figure 1. Chemical structures of fused thiophene-split or continuous sequence oligothiophenes

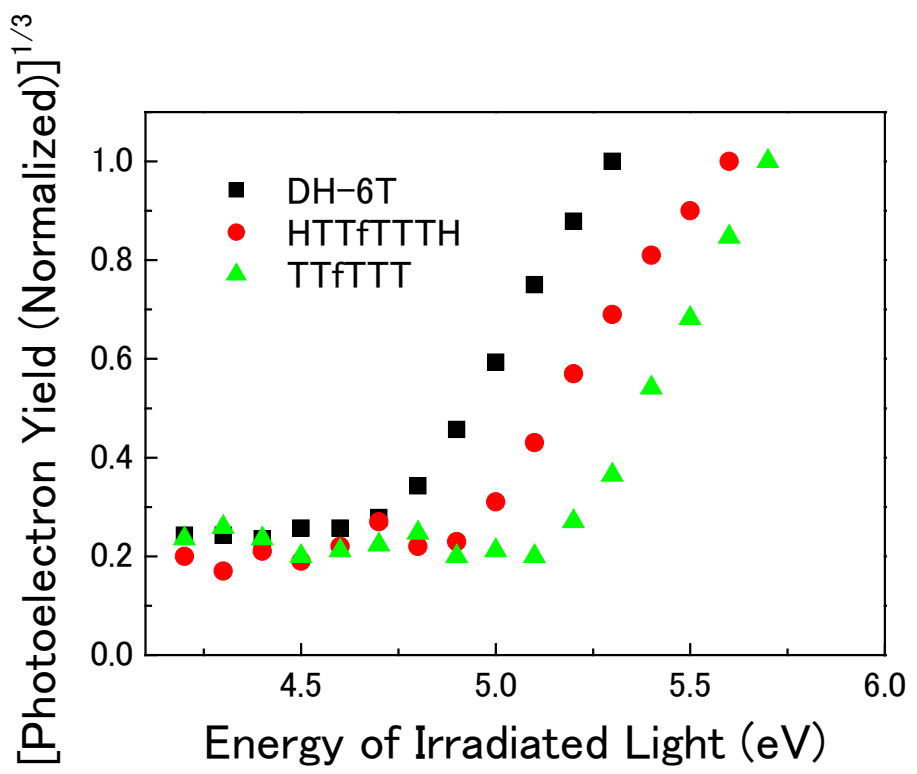

Figure 2. Photoelectron emission yield spectra of oligothiophenes. 


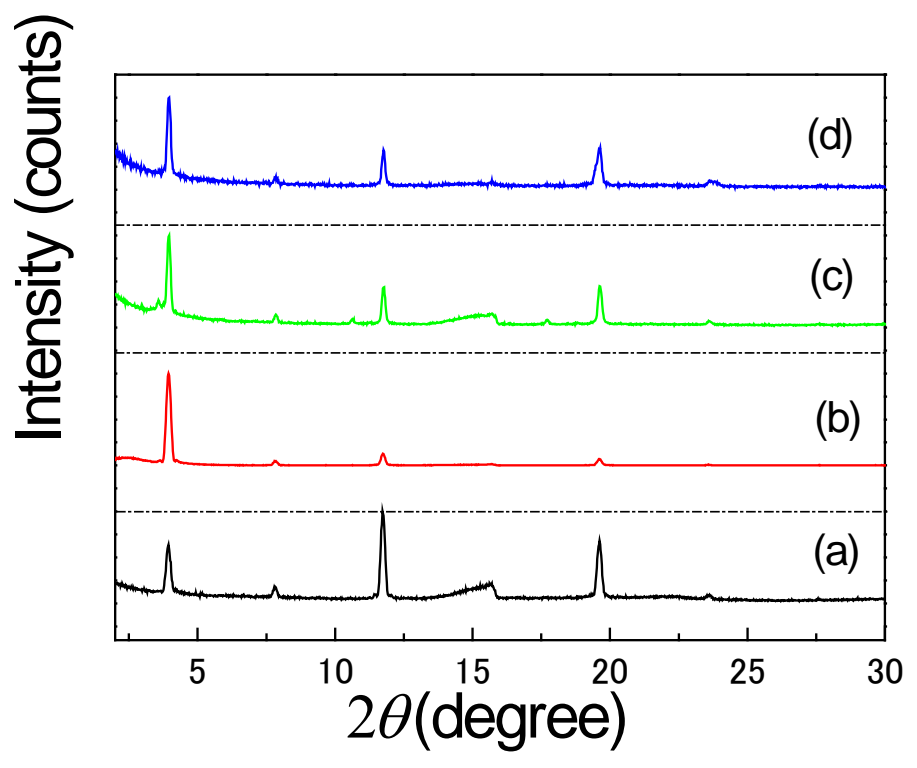

Figure 3. XRD patterns of TTfTTT thin films deposited on $\mathrm{Si} / \mathrm{SiO}_{2}$ with substrate control at (a) room temperature, (b) $80^{\circ} \mathrm{C}$, (c) $100^{\circ} \mathrm{C}$, and (d) $120^{\circ} \mathrm{C}$.

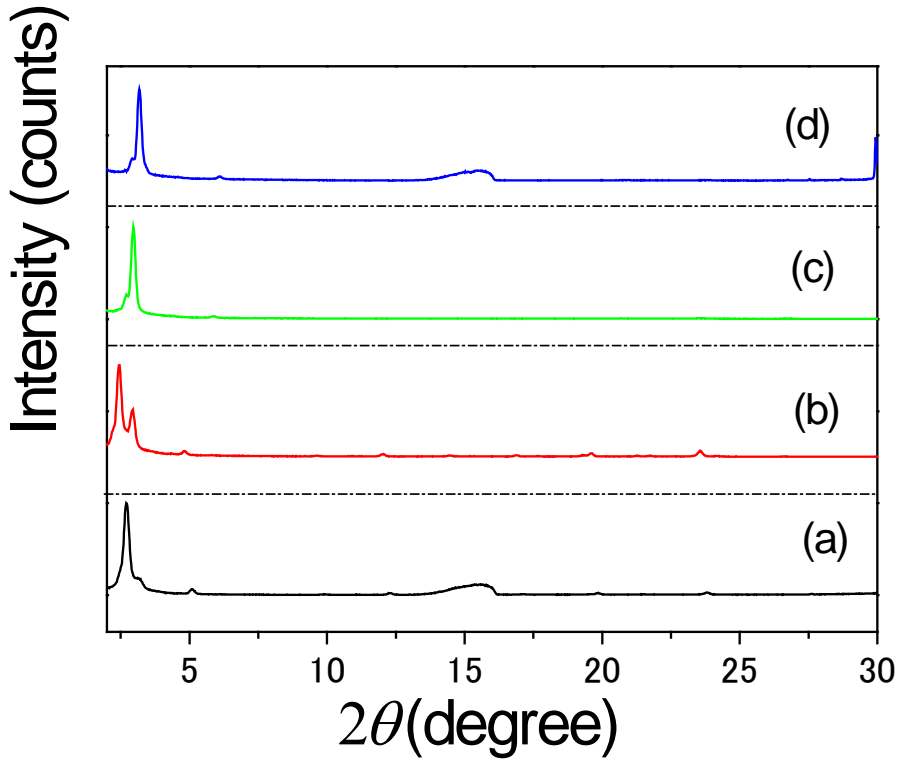

Figure 4. XRD patterns of HTTfTTTH thin films deposited on $\mathrm{Si} / \mathrm{SiO}_{2}$ without substrate control (a) no annealing and after annealing at (b) $80^{\circ} \mathrm{C}$, (c) $100^{\circ} \mathrm{C}$, and (d) $120^{\circ} \mathrm{C}$. 


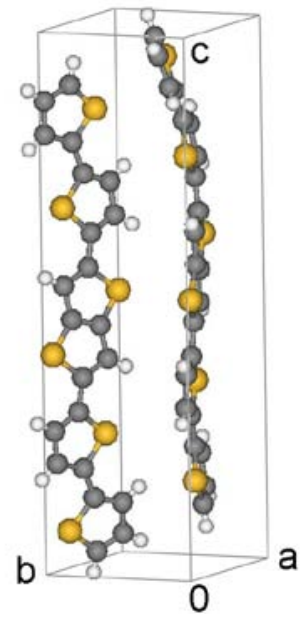

Figure 5. TTfTTT unit cell. (Crystal class: monoclinic, Space group: P21, Cell Constants: $a=$ $\left.5.8293 \AA ; b=7.2580 \AA ; c=22.700 \AA ; \beta=94.966^{\circ}\right)$. The crystal structure has been deposited at the Cambridge Crystallographic Data Centre and allocated the deposition number Summary of Data CCDC 697364 

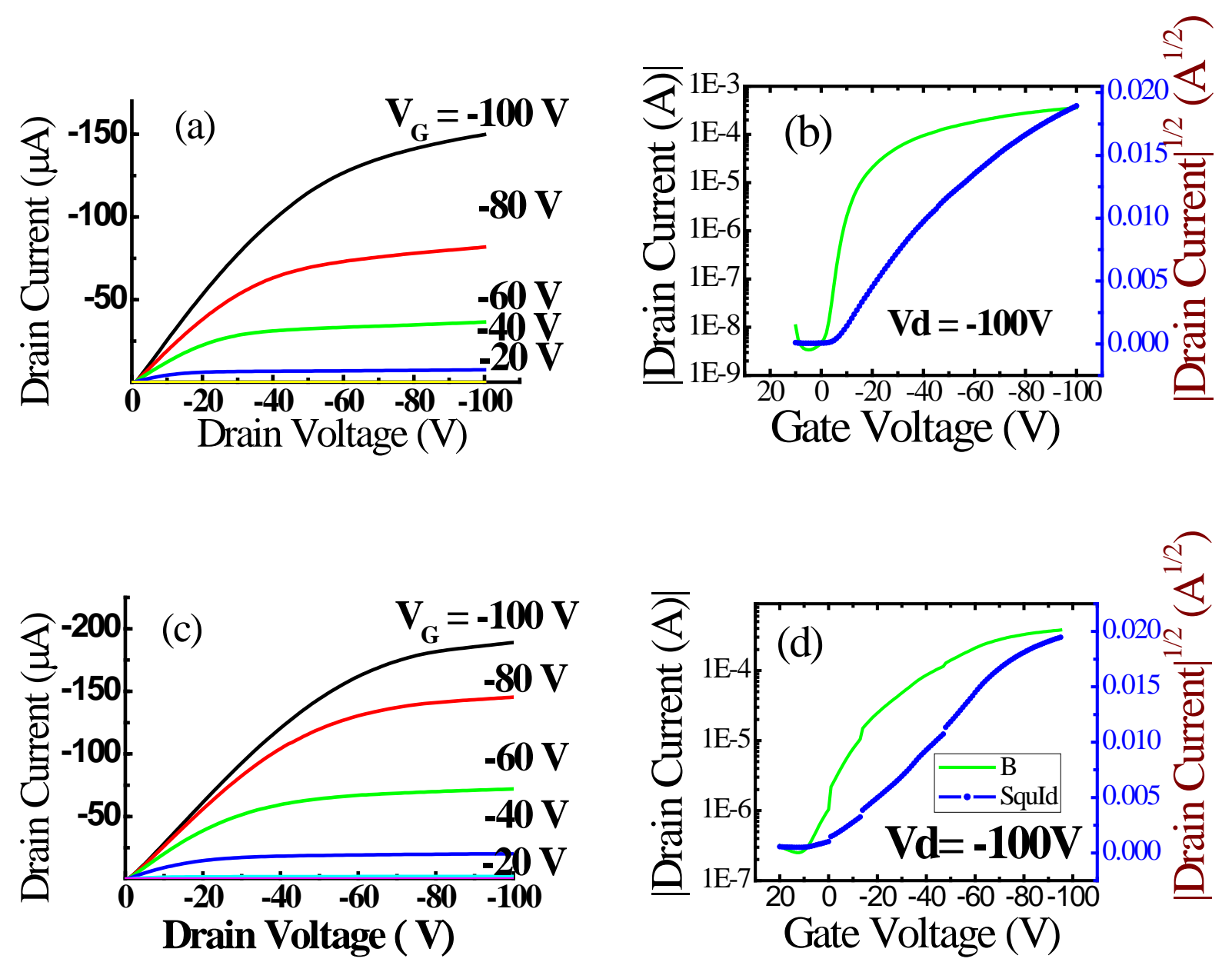

Figure 6. $I_{D}-V_{D}$ and $I_{D}-V_{G}$ characteristics of $(a, b)$ TTfTTT and (c, d) HTTfTTTH. 
(a)
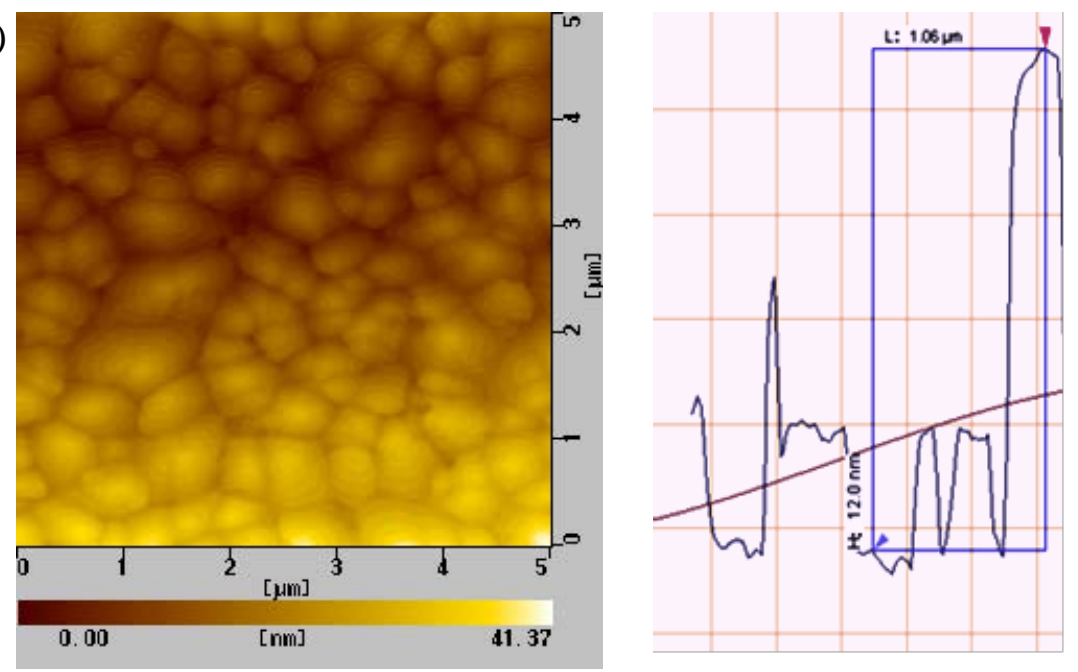

(b)

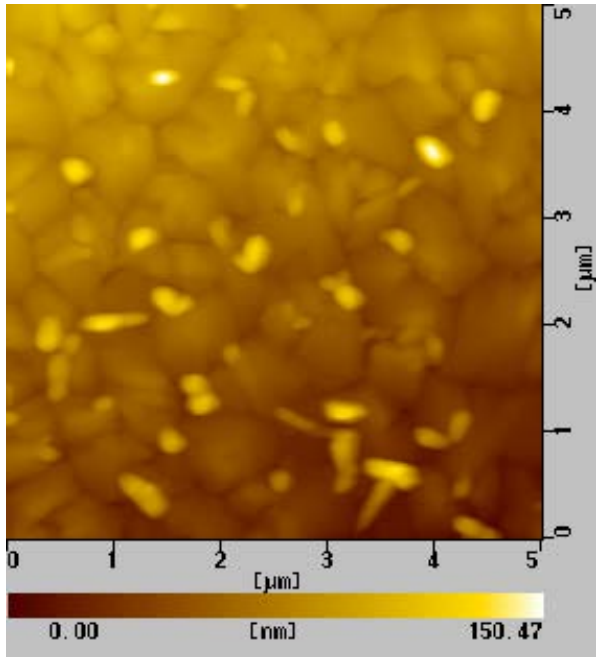

(c)

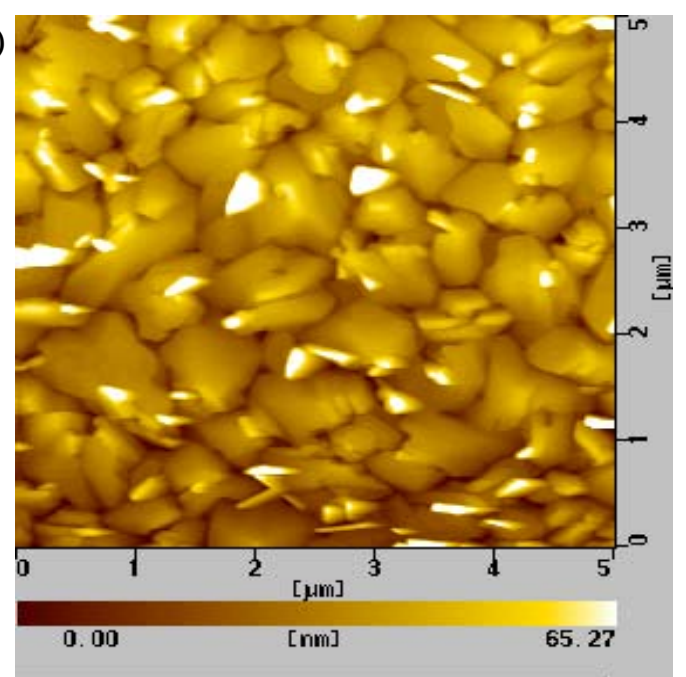

(d)

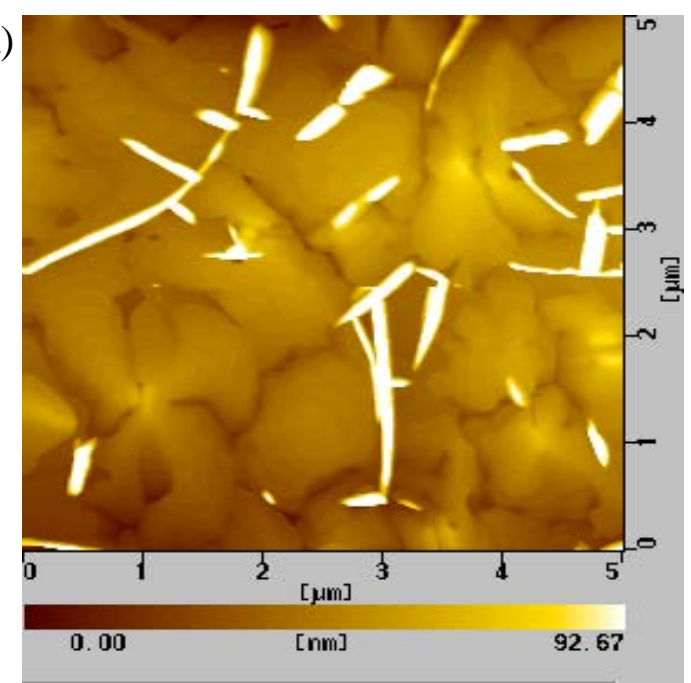

Figure 7. AFM of TTfTTT thin films deposited on $\mathrm{Si} / \mathrm{SiO}_{2}$ with substrate control at (a) room temperature and the step height of grains, (b) $80^{\circ} \mathrm{C}$, (c) $100^{\circ} \mathrm{C}$, (d) $120^{\circ} \mathrm{C}$. 
(a)

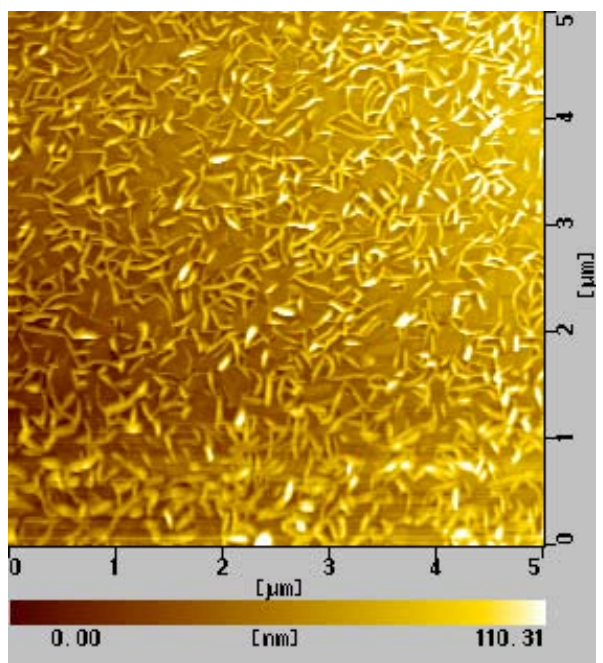

(c)

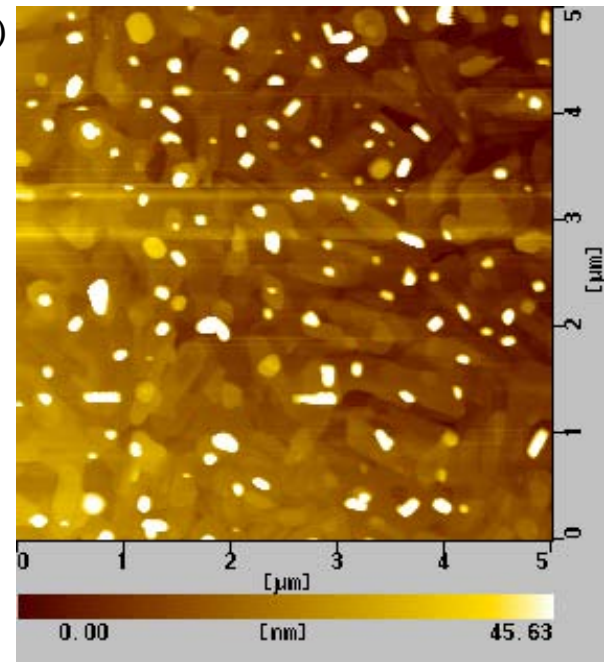

(b)

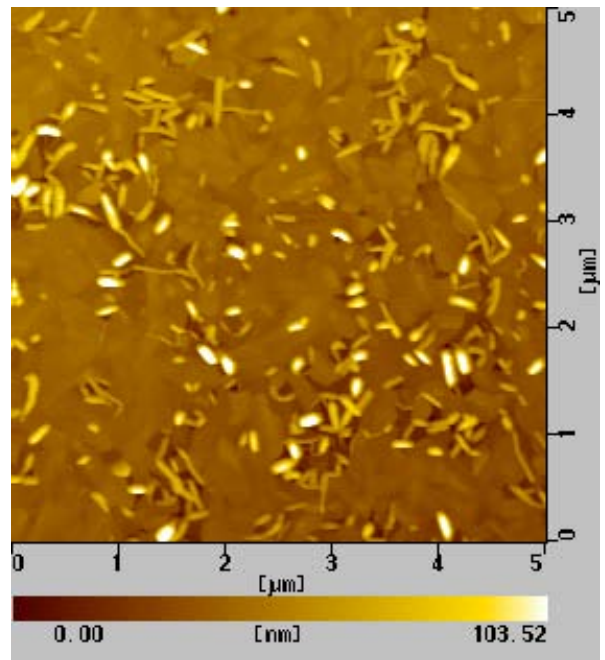

(d)

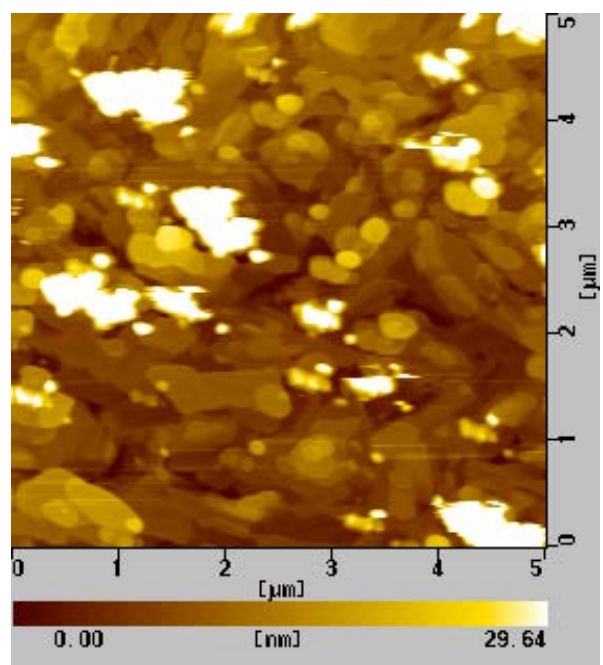

Figure 8. AFM of HTTfTTTH thin films deposited on $\mathrm{Si} / \mathrm{SiO}_{2}$ without substrate control (a) no annealing and after annealing at (b) $80^{\circ} \mathrm{C}$, (c) $100^{\circ} \mathrm{C}$, and (d) $120^{\circ} \mathrm{C}$. 


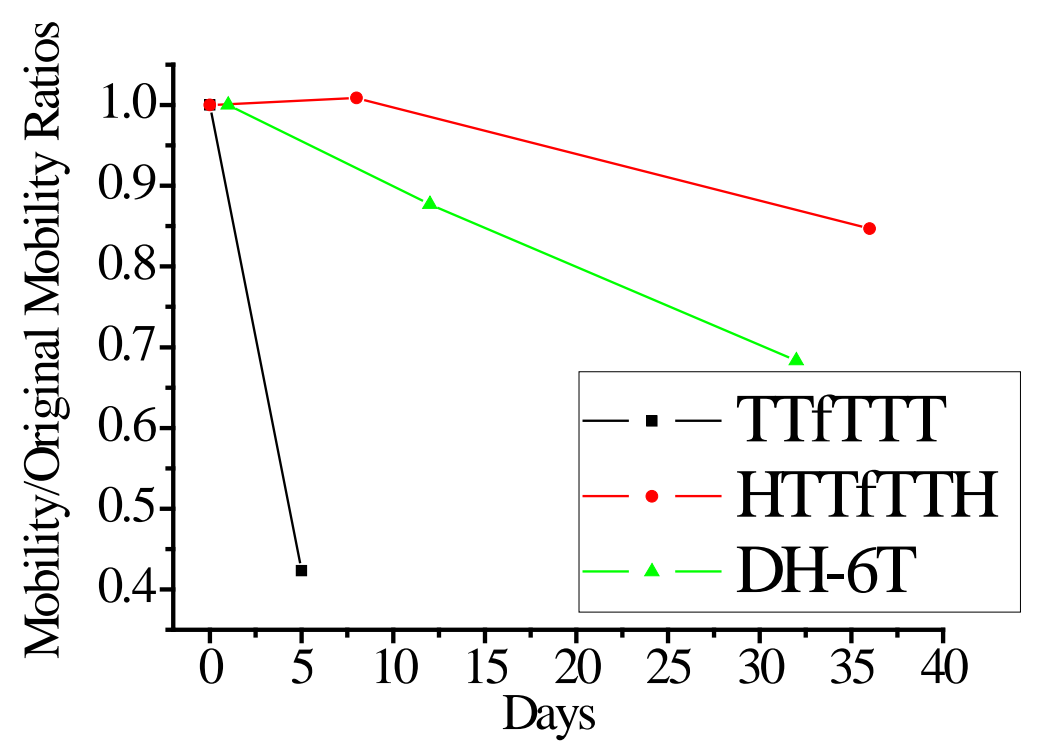

Figure 9. The mobility stabilities of TTfTTT, HTTfTTTH and DH-6T in atmosphere 